\title{
Skin anomalies in acromegalic patients (Review of the practical aspects)
}

\author{
FLORICA SANDRU $^{1,2}$, ADELINA POPA $^{2}$, DAN NICOLAE PADURARU ${ }^{3,4}$, \\ ALEXANDRU FILIPESCU $^{5,6}$, MARA CARSOTE ${ }^{7,8}$ and ADINA GHEMIGIAN ${ }^{7,8}$ \\ ${ }^{1}$ Department of Dermatology, 'Carol Davila' University of Medicine and Pharmacy, 050474 Bucharest; \\ ${ }^{2}$ Department of Dermatology, 'Elias' Emergency Hospital, 011461 Bucharest; ${ }^{3}$ Department of General Surgery, \\ 'Carol Davila' University of Medicine and Pharmacy, 050474 Bucharest; ${ }^{4}$ Department of General Surgery, \\ University Emergency Hospital, 050098 Bucharest; ${ }^{5}$ Department of Obstetrics and Gynecology, \\ 'Carol Davila' University of Medicine and Pharmacy, 050474 Bucharest; ${ }^{6}$ Department of Obstetrics \\ and Gynecology, 'Elias' Emergency Hospital, 022461 Bucharest; ${ }^{7}$ Department of Endocrinology, \\ 'Carol Davila' University of Medicine and Pharmacy, 050474 Bucharest; ${ }^{8}$ Department of Endocrinology, \\ 'C. I. Parhon' National Institute of Endocrinology, 011863 Bucharest, Romania
}

Received July 12, 2021; Accepted August 11, 2021

DOI: $10.3892 / \mathrm{etm} .2021 .10765$

\begin{abstract}
Acromegaly is a hormonal disorder which occurs as the result of growth hormone $(\mathrm{GH})$ and insulin growth factor 1 (IGF-1) over-secretion; both hormones are related to skin anomalies. The skin acts as a large endocrine organ, hosting GH receptors in every cell while IGF-1 receptors are expressed only in keratinocytes. This review is a literature review of skin anomalies found in acromegaly, either related to the disease itself or associated with related complications such as secondary diabetes mellitus, or involving associated conditions such as genetic syndromes. The following clinical points are mentioned as follows. Excessive skin and enlargement of soft tissue are due to glycosaminoglycan deposits, edema, and hyperhidrosis (mostly facial and acral). Acanthosis nigricans, a body fold dermatosis associated with insulin resistance, involves local or diffuse hyperkeratotic plaques with or without hyperpigmentation, caused by growth factors including GH/IGF-1. Other findings include cherry angiomas (due to the effects of lipid anomalies on small vessels); oily skin features with keratosis, epidermoid cysts, crochordons,
\end{abstract}

Correspondence to: Dr Alexandru Filipescu, Department of Obstetrics and Gynecology, 'Carol Davila' University of Medicine and Pharmacy, 37 Dionisie Lupu Street, 050474 Bucharest, Romania E-mail: afilipescu@hotmail.com

Abbreviations: EMT, epithelial-to-mesenchymal transition; GH, growth hormone; GH-R, growth hormone receptor; HR, hazard ratio; IGF, insulin growth factor; lncRNAs, long noncoding RNAs; MEN1, multiple endocrine neoplasia type 1

Key words: acromegaly, growth hormone, IGF1, skin, dermatologic, diabetes mellitus, angiomas, acanthosis nigricans, melanoma, MEN1 syndrome pseudo-acanthosis nigricans; a potentially higher prevalence of varicose veins and psoriasis; low level of evidence for basal cell carcinoma, respective hidroadenitis suppurativa has been noted. In addition, complicated uncontrolled secondary diabetes mellitus (DM) may result in necrobiosis lipoidica diabeticorum, diabetic dermopathy, skin bacterial infections, dermatological complications of diabetic neuropathy, and nephropathy. Finally, associated hereditary syndromes may cause collagenomas, fibromas/angiofibromas, lipomas in multiple endocrine neoplasia type 1 (MEN1) syndrome; café-au-lait macules, early onset neurofibromas, juvenile xanthogranuloma (involving non-Langerhans cell histiocytes), and intertriginous freckling in neurofibromatosis type 1. Clinical findings are differentiated from pseudo-acromegaly such as pachydermoperiostosis. Iatrogenic rash, lipodystrophy (lipoatrophy with/without lipohypertrophy) are rarely reported after pegvisomant/somatostatin analogues or after insulin use for DM. Experiments using human cell lines have shown that $\mathrm{GH} / \mathrm{IGF}-1$ over-secretion are prone to epithelial-to-mesenchymal transition (EMT) in melanoma. In non-acromegalic subjects, the exact role of GH/IGF-1 in skin tumorigenesis is yet to be determined. Skin in acromegaly speaks for itself, either as the first step of disease identification or as a complication or part of a complex syndromic context.

\section{Contents}

1. Introduction

2. Aim of the review

3. GH/IGF-1 and melanoma

4. Syndromic context

5. Acanthosis nigricans

6. Other dermatological findings

7. Conclusions 


\section{Introduction}

Acromegaly is caused by a pituitary somatotropinoma in $95 \%$ of cases. The complications are due to an excess in growth hormone $(\mathrm{GH})$ or insulin growth factor 1 (IGF-1) or both; females and males are similarly affected; the peak incidence is between 40 and 50 years of age; $5 \%$ of cases are gigantism; $10 \%$ of tumors co-secrete prolactin; and $5 \%$ of cases are detected below the age of 20 years (1). A multitude of complications are related to abnormal imbalance and to the presence of a pituitary mass, overall impacting the quality of life, morbidity and mortality of the patients (2).

Acromegaly occurs as the result of GH and IGF-1 over-secretion; skin anomalies are caused by both hormones (3). Skin, a large endocrine organ, has receptors for GH at all cell types while IGF-1 receptors are only expressed at the level of keratinocytes in the epidermis (4).

Excessive skin and enlargement of soft tissue are due to glycosaminoglycan deposits, edema, hyperhidrosis, mostly at the level of the extremities (acral) and face $(5,6)$.

Facial features and skin changes in addition to bone and joint modifications need to be differentiated from other conditions that are not induced by GH/IGF-1 excess, which are termed 'acromegaloidism' or 'pseudo-acromegaly' (7). In addition, pachydermoperiostosis involves pachyderma, periosteal hypertrophy and hyperhidrosis, with an acromegaly-like aspect (8). This is a hereditary condition also affecting the face, hands and feet (9).

Skin rash has been reported in relationship to specific therapy against GH excess such as pegvisomant or somatostatin analogues (10). Lipodystrophy, either lipoatrophy or lipohypertrophy, may be associated with these drugs as well as insulin in severe secondary cases of GH-induced diabetes mellitus (DM) (11).

\section{Aim of the review}

We aimed to introduce the clinical aspects of the dermatological findings in acromegaly on a multidisciplinary perspective.

This is a literature review of skin anomalies found in acromegaly, either related to the disease itself, or related to its complications such as secondary DM, or involving associated conditions such as genetic syndromes. The research is based on PubMed. The key words used were based on different combinations: 'acromegaly', 'diabetes mellitus', 'MEN1 syndrome', on the one hand, respective 'skin', 'achanthos nigricans', 'angioma', 'melanoma', on the other hand. The selection of 60 cited papers is based on clinical relevance. We included papers published between 2011 and 2021.

\section{GH/IGF-1 and melanoma}

GH/GH-R (receptor) and IGF are considered growth factors involved in different tumors; however, their role in melanoma is less clear (12). Experiments on human cell lines have shown that GH/IGF-1 excess results in EMT in melanoma (13). Somatostatin analogues may be future therapeutic targets in melanoma if somatostatin receptor expression is highlighted, as currently seen in GH-producing pituitary tumors and gastro-entero-pancreatic neuroendocrine neoplasia (14). In non-acromegalic subjects, the skin tumorigenic role of IGF-1 and GH/GH-R is yet to be determined (15). For instance, a large prospective study on 412,645 individuals (UK Biobank) who were followed up for 7.2 years showed a positive correlation between IGF-1 overexpression and melanoma with a modest hazard ratio (HR) of 1.08 (95\% CI, 1.01-1.15) (15). Yet, statistical correction of the data extracted from the same bio-base (394,388 individuals followed for 6.9 years) showed no association between IGF-1 and malignant melanoma (16).

IGF axes may also modulate chemotherapy resistance in melanoma through communication with long noncoding RNAs (lncRNAs) (17). Modulation of the estrogen receptor (ER)/IGF-1 signal transduction communication may explain the gender differences in melanoma presentation (18). Furthermore, IGF-1 receptor distribution on uveal melanoma explains its aggressive profile, especially the risk of hepatic spreading (19). Pristimerin may contra-regulate the IGF-1 receptor downstream in uveal melanoma, and its use in clinical practice is under evaluation (19).

In addition, downregulation of the IGF-1 receptor in melanoma may enhance the tumoral cell response to mitogen-activated protein kinase (MAPK) inhibitors (20). When it comes to acromegalic patients, a higher risk of various cancers has been reported such as colonic carcinoma (21). However, this is mostly related to uncontrolled disease, and recent data showed a massive improvement of the oncologic risk in these patients during the last decade due to multi-modal therapy (22). Overall, no specific risk has been reported in relationship with malignant melanoma in acromegalic subjects; neither case finding strategies in individuals diagnosed with melanoma in order to seek a source of GH/IGF-1 excess $(23,24)$.

\section{Syndromic context}

Carney complex includes thyroid, adrenal, and gonadal anomalies as well as acromegaly in association with myxomas which are located at different regions including the skin (25). Additional lesions in this PRKARIA (protein kinase CAMP-dependent type I regulatory subunit $\alpha$ ) gene-related autosomal dominant condition include blue nevi, pigmented spots, lentiginosis features, and psamommatous melanotic schwannomas (26).

McCune-Albright syndrome, exceptionally associated giganto-acromegaly, requires a differentiation of facial dysplasia to GH excess-associated features. Also, other skin anomalies that are found in these patients include café-au-lait spots (27).

Pituitary somatotropinomas have been reported in some subjects confirmed with neurofibromatosis type 1 (28-30). This is not a traditional endocrinopathy of the syndrome, in contrast to pheocromocytomas or somatostatinomas; they may also be associated with other anomalies of the glucose profile that, on a long term, might express on the skin among other complications $(31,32)$. Individuals presenting this autosomal dominant RASopathy may have multiple dermatological anomalies such as café-au-lait macules, neurofibromas of different types with early onset at childhood and adolescence (even oral neurofibromas have been recently reported), nevus anemicus, juvenile xanthogranuloma (a rare condition of non-Langerhans cell histiocytes), and intertriginous 
freckling (33-35). Pigmented skin tags are found in individuals diagnosed with GH-producing hypophyseal tumors with lentiginous-like aspects which need to be differentiated from similar skin anomalies in neurofibromatosis type 1 (36). Melanocytic proliferation in neurofibromatosis type 1 may be suboptimally screened nowadays (37).

Non-endocrine manifestations of multiple endocrine neoplasia type 1 syndrome may include skin findings such as basocellular carcinoma, collagenomas, fibromas/angiofibromas, low-grade fibromyxoid sarcoma, and lipomas $(38,39)$. Since there is no genotype-phenotype correlation in this $M E N-1$ gene-related hereditary syndrome, the clinical aspects of acromegaly or of different dermatological lesions cannot be exclusively predicted based on genetic assessments $(40,41)$.

\section{Acanthosis nigricans}

Endocrine-related conditions associated with acanthosis nigricans include DM, acromegaly, polycystic ovary syndrome, Cushing syndrome, and obesity with insulin resistance (the skin lesion is the hallmark of insulin resistance) (42). Dermoscopic and skin biopsy might bring supplementary information (43). Androgen excess may also cause it, also inducing hirsutism (hirsutism has been reported in acromegaly and prolactinoma, too, as well as acne) (44). Paraneoplastic presentation of acanthosis nigricans has been described (45).

Acanthosis nigricans represents a hyperplastic muco-cutaneous lesion that is also reported in teenagers and the pediatric population; it is due to local growth factors including GH/IGF-1 (46). It may represent an early sign of an endocrine-metabolic anomaly which is mainly focused on insulin resistance (47). Hyperkeratotic plaques are either local or diffuse, associated with hyperpigmentation; they are part of a fold dermatosis and exceptionally they are reported at the oral mucosa level (48).

\section{Other dermatological findings}

Cherry angiomas have been reported in acromegaly according to some studies with a higher prevalence than the global population (49). Generally, cherry angiomas are related to aging or to different pro-angiogenesis elements, despite the fact that the exact cause remains unknown (50). Most angiogenetic factors involve small vessel obstruction due to anomalies of lipid profile as seen in acromegaly (51). Oily aspect of the skin may be associated with keratosis, epidermoid cysts and crochordons and pseudo-acanthosis nigricans (52).

The GH/IGF-1 system acts as a prone of vessel proliferation such as retinal vessels, but also dermal; varicose veins in the legs also have been found with increased prevalence according to some authors (53). A potential increased risk of developing psoriasis has been suggested (54). Rare cases of co-incidental basal cell carcinoma are reported (55). Case reports with hidradenitis suppurativa, a follicular condition, have been linked to acromegalic status, but the association is not typical (56). A few studies have shown a higher prevalence of autoimmune conditions such as Hashimoto thyroiditis among individuals with acromegaly; the most common non-endocrine autoimmune correlate of chronic autoimmune thyroiditis is vitiligo (57). In cases with severe, complicated, uncontrolled, secondary (acromegaly-related) DM, we need to take into consideration the large area of multiple dermatological complications such as necrobiosis lipoidica diabeticorum, diabetic dermopathy, skin bacterial infections, scleroderma, skin complications of diabetic neuropathy, and nephropathy (58-60).

\section{Conclusions}

Skin in acromegaly speaks for itself, either as a first step of disease identification or as a complication or part of a syndromic context. A multidisciplinary team is needed for the management of acromegalic patients, including a dermatological assessment.

\section{Acknowledgements}

Not applicable.

Funding

No funding was received.

\section{Availability of data and materials}

Not applicable.

\section{Authors' contributions}

FS drafted the manuscript and critically revised the final form. AP drafted the manuscript, and DNP researched the literature. $\mathrm{AF}$ is the corresponding author and researched the literature. MC drafted the manuscript and researched the references, and AG revised the bibliography and approved the final form. All authors read and approved the final manuscript for publication.

\section{Ethics approval and consent to participate}

Not applicable.

\section{Patient consent for publication}

Not applicable.

\section{Competing interests}

The authors declare that they have no competing interests.

\section{References}

1. Vilar L, Vilar CF, Lyra R, Lyra R and Naves LA: Acromegaly: Clinical features at diagnosis. Pituitary 20: 22-32, 2017.

2. Broersen LHA, Zamanipoor Najafabadi AH, Pereira AM, Dekkers OM, van Furth WR and Biermasz NR: Improvement in symptoms and health-related quality of life in acromegaly patients: A systematic review and meta-analysis. J Clin Endocrinol Metab 106: 577-587, 2021

3. Giustina A, Barkhoudarian G, Beckers A, Ben-Shlomo A, Biermasz N, Biller B, Boguszewski C, Bolanowski M, Bollerslev J, Bonert $\mathrm{V}$, et al: Multidisciplinary management of acromegaly: A consensus. Rev Endocr Metab Disord 21: 667-678, 2020 . 
4. Kanaka-Gantenbein C, Kogia C, Abdel-Naser MB and Chrousos GP: Skin manifestations of growth hormone-induced diseases. Rev Endocr Metab Disord 17: 259-267, 2016.

5. Degirmentepe EN, Gungor S, Kocaturk E, Kiziltac U, Adas M, Ozekinci S and Khachemoune A: Dermatologic manifestations of acromegaly: A case in point and a focused review. Dermatol Online J 23: 13030/qt50s903qh, 2017.

6. Lause M, Kamboj A and Fernandez Faith E: Dermatologic manifestations of endocrine disorders. Transl Pediatr 6: 300-312, 2017

7. Alotaibi A, Habib A, Osman M, Alzahrani K and Alzahrani F: Pseudoacromegaly associated with non-functioning pituitary adenoma. Eur J Case Rep Intern Med 7: 001950, 2020.

8. Joshi A, Nepal G, Shing YK, Panthi HP and Baral S: Pachydermoperiostosis (touraine-solente-gole syndrome): A case report. J Med Case Rep 13: 39, 2019.

9. Prerna, Ghosh R, Barua JK and Das AK: Pachydermoperiostosis mimicking acromegaly: A case report. Indian Dermatol Online J 9: 182-184, 2018

10. Tritos NA, Chanson P, Jimenez C, King D, Jönsson PJ, Klibanski A and Biller BM: Effectiveness of first-line pegvisomant monotherapy in acromegaly: An ACROSTUDY analysis. Eur J Endocrinol 176: 213-220, 2017.

11. Gentile S, Strollo F and Ceriello A; AMD-OSDI Injection Technique Study Group: Lipodystrophy in insulin-treated subjects and other injection-site skin reactions: Are we sure everything is clear? Diabetes Ther 7: 401-409, 2016.

12. Osher E and Macaulay VM: Therapeutic targeting of the IGF axis. Cells 8: 895, 2019

13. Qian Y, Basu R, Mathes SC, Arnett NA, Duran-Ortiz S, Funk KR, Brittain AL, Kulkarni P, Terry JC, Davis E, et al: Growth hormone upregulates mediators of melanoma drug efflux and epithelial-to-mesenchymal transition in vitro and in vivo. Cancers (Basel) 12: 3640, 2020.

14. Valea A, Ghervan C, Carsote M, Morar A, Iacob I, Tomesc F, Pop DD and Georgescu C: Effects of combination therapy: Somatostatin analogues and dopamine agonists on GH and IGF levels in acromegaly. Clujul Med 88: 310-313, 2015.

15. Qian F and Huo D: Circulating insulin-like growth factor-1 and risk of total and 19 site-specific cancers: Cohort study analyses from the UK Biobank. Cancer Epidemiol Biomarkers Prev 29: 2332-2342, 2020.

16. Knuppel A, Fensom GK, Watts EL, Gunter MJ, Murphy N, Papier K, Perez-Cornago A, Schmidt JA, Smith Byrne K, Travis RC and Key TJ: Circulating insulin-like growth factor-i concentrations and risk of 30 cancers: Prospective analyses in UK Biobank. Cancer Res 80: 4014-4021, 2020.

17. An LF, Huang JW, Han X and Wang J: Downregulation of lncRNA H19 sensitizes melanoma cells to cisplatin by regulating the miR-18b/IGF1 axis. Anticancer Drugs 31: 473-482, 2020.

18. Yuan TA, Yourk V, Farhat A, Guo KL, Garcia A, Meyskens FL and Liu-Smith F: A possible link of genetic variations in ER/IGF1R pathway and risk of melanoma. Int J Mol Sci 21: 1776, 2020

19. Xie X, Xie S, Xie C, Fang Y, Li Z, Wang R and Jiang W: Pristimerin attenuates cell proliferation of uveal melanoma cells by inhibiting insulin-like growth factor-1 receptor and its downstream pathways. J Cell Mol Med 23: 7545-7553, 2019.

20. Suleymanova N, Crudden C, Worrall C, Dricu A, Girnita A and Girnita L: Enhanced response of melanoma cells to MEK inhibitors following unbiased IGF-1R down-regulation. Oncotarget 8 : 82256-82267, 2017.

21. Terzolo M, Puglisi S, Reimondo G, Dimopoulou C and Stalla GK: Thyroid and colorectal cancer screening in acromegaly patients: Should it be different from that in the general population? Eur J Endocrinol 183: D1-D13, 2020

22. Kasuki L, Rocha PDS, Lamback EB and Gadelha MR: Determinants of morbidities and mortality in acromegaly. Arch Endocrinol Metab 63: 630-637, 2019.

23. $\mathrm{Ku} \mathrm{CR}$, Melnikov V, Zhang Z and Lee EJ: Precision therapy in acromegaly caused by pituitary tumors: How close is it to reality? Endocrinol Metab (Seoul) 35: 206-216, 2020.

24. Sandru F, Draghici CC, Predescu T, Constantin M, Petca RC, Constantin T, Petca A and Cristian Dumitrascu M: Regressive melanoma in a female patient: A case report. Exp Ther Med 20: $87-90,2020$.

25. Shirinpour Z, Farhangiyan Z, Akiash N and Rashidi H: Recurrent cardiac and skin myxomas along with acromegaly: A case report of carney complex. ARYA Atheroscler 16: 146-150, 2020.

26. Kamilaris CDC, Faucz FR, Voutetakis A and Stratakis CA: Carney complex. Exp Clin Endocrinol Diabetes 127: 156-164, 2019.
27. Subbiah S, Palikhe G, Bhadada SK, Mukherjee KK and Bhansali A: Acrogigantism and facial asymmetry: McCune-Albright syndrome. J Pediatr Endocrinol Metab 24: 835-837, 2011.

28. Hozumi K, Fukuoka H, Odake Y, Takeuchi T, Uehara T, Sato T, Inoshita N, Yoshida K, Matsumoto R, Bando H, et al: Acromegaly caused by a somatotroph adenoma in patient with neurofibromatosis type 1. Endocr J 66: 853-857, 2019.

29. Hannah-Shmouni F and Stratakis CA: Growth hormone excess in neurofibromatosis 1. Genet Med 21: 1254-1255, 2019.

30. Cambiaso P, Galassi S, Palmiero M, Mastronuzzi A, Del Bufalo F, Capolino R, Cacchione A, Buonuomo PS, Gonfiantini MV, Bartuli A, et al: Growth hormone excess in children with neurofibromatosis type-1 and optic glioma. Am J Med Genet A 173 2353-2358, 2017.

31. Sandru F, Carsote M, Valea A, Albu SE, Petca RC and Dumitrascu MC: Somatostatinoma: Beyond neurofibromatosis type 1 (review). Exp Ther Med 20: 3383-3388, 2020.

32. Valea A, Carsote M, Ghervan C and Georgescu C: Glycemic profile in patients with acromegaly treated with somatostatin analogue. J Med Life 8 (Spec Issue): 82-86, 2015.

33. Ozarslan B, Russo T, Argenziano G, Santoro C and Piccolo V: Cutaneous findings in neurofibromatosis type 1. Cancers (Basel) 13: 463, 2021.

34. Buchholzer S, Verdeja R and Lombardi T: Type I neurofibromatosis: Case report and review of the literature focused on oral and cutaneous lesions. Dermatopathology (Basel) 8: 17-24, 2021.

35. Kundak $S$ and Cakır Y: Juvenile xanthogranuloma: Retrospective analysis of 44 pediatric cases (single tertiary care center experience). Int J Dermatol 60: 564-569, 2021

36. Anderson S: Café au lait macules and associated genetic syndromes. J Pediatr Health Care 34: 71-81, 2020.

37. Ntala $\mathrm{C}$ and Biswas A: Spectrum of melanocytic proliferation/differentiation in a large series of cutaneous neurofibromas: An under-recognized histopathologic phenomenon and potential clue for neurofibromatosis type 1 . Am J Dermatopathol 42: $165-172,2020$

38. Radman M and Milicevic T: A novel mutation of the MEN1 gene in a patient with multiple endocrine neoplasia type 1 and recurrent fibromyxoid sarcoma-a case report. BMC Med Genet 21: 190, 2020.

39. Pérez AD, Yu S and North JP: Multiple cutaneous collagenomas in the setting of multiple endocrine neoplasia type 1. J Cutan Pathol 42: 791-795, 2015.

40. Sandru F, Carsote M, Albu SE, Valea A, Petca A and Dumitrascu MC: Glucagonoma: From skin lesions to the neuroendocrine component (review). Exp Ther Med 20: 3389-3393, 2020.

41. Brown GT, Cowen EW and Lee CC: Malignant melanoma masquerading as an angiofibroma in a patient with MEN-1. JAMA Dermatol 151: 105-106, 2015.

42. Keen MA, Shah IH and Sheikh G: Cutaneous manifestations of polycystic ovary syndrome: A cross-sectional clinical study. Indian Dermatol Online J 8: 104-110, 2017.

43. Pardeshi SS, Khemani UN, Kamath RR, Kura MM and Jafferany M: Therapeutic implications of dermoscopic findings in acanthosis nigricans: A clinical and histopathological study. Dermatol Ther 33: e14521, 2020.

44. Yilmaz B and Yildiz BO: Endocrinology of hirsutism: From androgens to androgen excess disorders. Front Horm Res 53: 108-119, 2019.

45. Ng HY: Acanthosis nigricans in obese adolescents: Prevalence, impact, and management challenges. Adolesc Health Med Ther 8: 1-10, 2016.

46. De Sanctis V, Soliman A, Marsciani A, Timoncini G, Reggiani L, Zucchini A and Altieri E: Acanthosis nigricans in adolescents: A practical approach. Georgian Med News: 73-78, 2013.

47. Bhagyanathan M, Dhayanithy D, Parambath VA and Bijayraj R: Acanthosis nigricans: A screening test for insulin resistance-an important risk factor for diabetes mellitus type-2. J Family Med Prim Care 6: 43-46, 2017.

48. Kutlubay Z, Engin B, Bairamov O and Tüzün Y: Acanthosis nigricans: A fold (intertriginous) dermatosis. Clin Dermatol 33: 466-470, 2015

49. Akoglu G, Metin A, Emre S, Ersoy R and Cakir B: Cutaneous findings in patients with acromegaly. Acta Dermatovenerol Croat 21: 224-229, 2013.

50. Buslach N, Foulad DP, Saedi N and Mesinkovska NA: Treatment modalities for cherry angiomas: A systematic review. Dermatol Surg 46: 1691-1697, 2020 
51. Darjani A, Rafiei R, Shafaei S, Rafiei E, Eftekhari H Alizade N, Gharaei Nejad K, Rafiee B and Najirad S: Evaluation of lipid profile in patients with cherry angioma: A case-control study in Guilan, Iran. Dermatol Res Pract 2018: 4639248, 2018.

52. Resende M, Bolfi F, Nunes Vdos S and Miot HA: Prevalence of dermatologic disorders in 15 patients with acromegaly. An Bras Dermatol 87: 166-168, 2012.

53. Füchtbauer L, Olsson DS, Coopmans EC, Bengtsson BÅ, Norrman LL, Neggers SJCMM, Hellström A and Johannsson G: Increased number of retinal vessels in acromegaly. Eur J Endocrinol 182: 293-302, 2020.

54. Haddad A, Ashkenazi RI, Bitterman H, Feldhamer I, Greenberg-Dotan S, Lavi I, Batat E, Bergman I, Cohen AD and Zisman D: Endocrine comorbidities in patients with psoriatic arthritis: A population-based case-controlled study. J Rheumatol 44: 786-790, 2017.
55. Bolfi F, Miot HA, Resende M, Mazeto GM, Romeiro FG, Yamashiro Fda $S$ and Nunes Vdos S: Frequency of various types of neoplasia in a group of acromegalic patients. Arq Bras Endocrinol Metabol 57: 612-616, 2013.

56. Scheinfeld N: Diseases associated with hidranitis suppurativa: Part 2 of a series on hidradenitis. Dermatol Online J 19: 18558, 2013.

57. Manavela M, Vigovich C, Danilowicz K, Juri A, Miechi L, Fernandez Valoni V and Bruno OD: Thyroid autoimmune disorders in patients with acromegaly. Pituitary 18: 912-915, 2015.

58. Falcone M, Meier JJ, Marini MG, Caccialanza R, Aguado JM, Del Prato S and Menichetti F: Diabetes and acute bacterial skin and skin structure infections. Diabetes Res Clin Pract 174: 108732, 2021

59. Papachristou S, Pafili K and Papanas N: Skin AGEs and diabetic neuropathy. BMC Endocr Disord 21: 28, 2021.

60. Naik PP and Farrukh SN: Clinical significance of diabetic dermatopathy. Diabetes Metab Syndr Obes 13: 4823-4827, 2020. 